\title{
FORMAÇÃO DE PREÇOS EM HOTELARIA: UM ESTUDO DE CASO
}

PRICE SETTING IN HOTEL MANAGEMENT: A CASE STUDY

LA FORMACIÓN DE PRECIOS EN HOTELERÍA: UN ESTUDIO DE CASO

Patricia Jung

Bacharel em Administração (UFFS)

patrícia_jung@outlook.com

Roberto M. Dall'Agnol

Universidade Federal da Fronteira Sul - UFFS / Professor Adjunto roberto.dallagnol@uffs.edu.br

Data de Submissão: 30/10/2014

Data de Aprovação: 30/11/2015

RESUMO: A formação de preços e os seus impactos na hotelaria de pequeno porte, em função das características peculiares ao setor, com significativos custos indiretos, riscos de ociosidade e acirramento competitivo, remetem a buscas por alternativas eficazes de controle de custos e estabelecimento dos preços de modo competitivo. A presente pesquisa, qualitativa e aplicada, por intermédio de estudo de caso, apresenta uma metodologia de formação de preços para um hotel de pequeno porte em Chapecó/SC, considerando os métodos de formação de preços e as peculiaridades do setor, com a aplicação do método de custeio $A B C$; e, complementarmente, com um estudo comparativo de mercado, envolvendo os preços possíveis com a aplicação dos custos identificados, tendo em vista os preços praticados no mercado concorrente. Ambas as situações foram consideradas também sob o prisma da rentabilidade e da ociosidade do investimento. Com base nesses elementos, apresentou-se uma sugestão de estrutura de preço de diárias para o hotel em estudo. As conclusões revelaram a imperatividade de conjugar custos e concorrência quando da formação de preços, sendo os primeiros necessários ao balizamento da situação financeira da organização e, o segundo, útil para o nivelamento das expectativas de rentabilidade diante do cenário competitivo.

Palavras-chave: Precificação. Hotelaria. Custos. 
ABSTRACT: Price formation and its impact on small hotels, depending on the particular characteristics to the sector, with significant indirect costs, risk of vacant rooms, and high levels of competitiveness, has led to a search for effective alternatives to control costs and establish prices competitively. This qualitative, research was applied through a case study, which presents a price formation method for a small hotel in the city of Chapecó/SC, considering the pricing methods and the peculiarities of the sector, with the application of the ABC method costing; To complement this, a comparative market study was also conducted, involving possible prices, with the application of the costs identified, based on the prices practiced in the competitor market. Both situations were considered from a perspective of profitability and the vacant rooms of the investment. Based on these elements, a price structure is suggested for the room rates of the hotel studied. The conclusions reveal an urgent need to combine costs and competition in the price formation; the former are necessary to support the financial situation of the organization, and the latter is useful for setting the expectations of profitability, faced with the competitive landscape.

Keywords: Pricing. Hotel Business. Costs.

RESUMEN: La formación de precios y sus impactos en la hotelería de pequeño porte, en función de las características peculiares del sector, con significativos costos indirectos, riesgos de ociosidad y radicalización competitiva, remiten a una búsqueda de alternativas eficaces para el control de costos y el establecimiento de los precios de forma competitiva. La presente investigación, cualitativa y aplicada por intermedio de un estudio de caso, presenta una metodología de formación de precios para un hotel de pequeño porte en Chapecó/SC, considerando los métodos de formación de precios y las peculiaridades del sector con la aplicación del método de costeo ABC. Se complementa con un estudio comparativo de mercado, incluyendo los precios posibles con la aplicación de los costos identificados, tomando en cuenta los precios practicados en el mercado concurrente. Ambas situaciones fueron consideradas también desde el punto de vista de la rentabilidad y de la ociosidad de la inversión. En base a estos elementos se presentó una propuesta de estructura de precio de diarias para el hotel en estudio. Las conclusiones revelaron lo imperativo de conjugar costos y concurrencia en la formación de precios; los primeros son necesarios para el balizamiento de la situación financiera de la organización y el segundo es útil para nivelar las expectativas de rentabilidad frente al panorama competitivo.

Palabras clave: Precificación. Hotelería. Costos.

INTRODUÇÃO

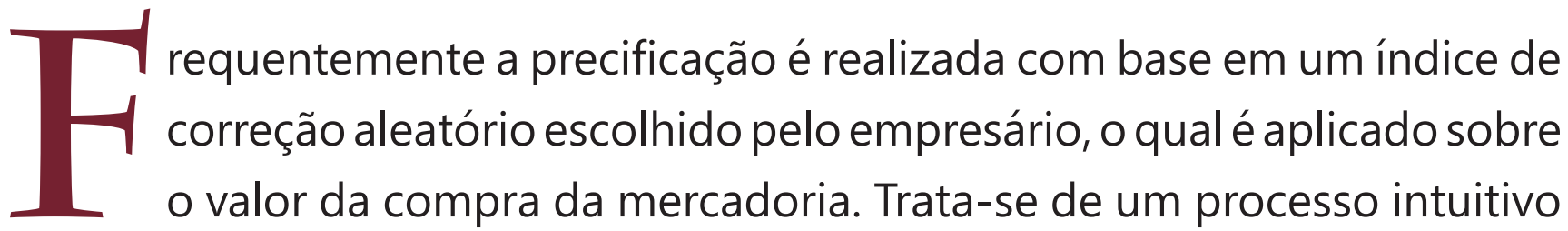
do gestor e que, raramente, compreende todos os elementos necessários para uma correta formação de preços. O que se evidencia nesse cenário é que são poucas as empresas, sobretudo, quando se referem a negócios de pequeno porte, que exploram o preço como uma vantagem competitiva (BRUNI; FAMÁ, 2012; MORANTE; JORGE, 2009). 
Cabe destacar que a formação de preços ultrapassa a simples definição de um valor monetário para um produto ou serviço, perpassando elementos de competitividade, mercado, demanda, produtos substitutos, relevância para o cliente/usuário, etc. Consequentemente, precificar, especialmente em um mercado competitivo, com uma gama diversificada de produtos e serviços, que assumem características distintas em diferentes níveis de especificidade, torna-se um processo complexo, cuja dinâmica requer atenção e disciplina. Portanto, apesar do sucesso organizacional não ser resultado direto das decisões sobre preços, estes, quando elaborados de modo precipitado, definitivamente podem comprometer a perpetuação dos negócios (BRUNI; FAMÁ, 2012; MORANTE; JORGE, 2009).

Fica claro que a precificação adequada influencia tanto a sobrevivência quanto a rentabilidade do negócio. $E$, à medida que a complexidade do ambiente e da organização aumenta, a gestão de formação de preços assume papel determinante em seu plano estratégico. Nessa perspectiva a apuração, a análise e o controle de custos revelam-se fundamentais para o processo de tomada de decisão sobre a formação de preços. Contudo, decisões sobre preços requerem avaliar a competitividade da empresa no mercado e a remuneração do capital investido, sem se descuidar das oscilações da demanda.

Constata-se, portanto, que formar preços envolve um cenário de relativa complexidade, remetendo à significância da utilização de um método e uma estratégia adequados para atender às diferentes variáveis interligadas nesse tipo de decisão.

No ramo hoteleiro, tal importância não poderia ser relegada, especialmente por se tratar de um setor em franca expansão nos últimos anos, em que a competitividade se eleva pelo crescimento das redes hoteleiras, que possuem eficientes sistemas de gestão. Face ao exposto, o presente trabalho buscou responder à seguinte problemática: Como estabelecer uma precificação adequada para as diárias de um hotel de pequeno porte na cidade de Chapecó/SC?

Diante disso, o objetivo do estudo foi de pesquisar alternativas para uma adequada formação de preços de diárias para um hotel de pequeno porte em Chapecó/SC, considerando duas dimensões: viabilidade financeira, com a cobertura de custos e despesas; e, competitividade de mercado, com o 
acompanhamento dos preços praticados pela concorrência. Em ambos os casos foram considerados os resultados possíveis do ponto de vista da rentabilidade do capital investido.

A pesquisa encontra justificativa por se tratar de estudo descritivo e aplicado à realidade local, mas extensivo a outras realidades similares, oferecendo conexões importantes entre aspectos teóricos e práticos de mercado. Alem disso, os resultados foram utilizados pela organização pesquisada, contribuindo de modo efetivo para a melhoria da gestão e ampliação da integração entre a pesquisa e a aplicação prática da ciência da Administração. Nesse mesmo âmbito, considerase relevante para a ciência e para as organizações, que ocorram transferências de conhecimentos a partir das teorias acerca de métodos e ferramentas de gestão para a prática da tomada de decisões, qualificando assim a gestão das organizações e imprimindo maior vitalidade na continuidade dos negócios.

Na presente pesquisa, qualitativa, aplicada e descritiva, a busca por elementos teóricos, via revisão bibliográfica, que possibilitassem conectar a formação de preços com seus desafios de manutenção financeira, competitividade e rentabilidade, norteou o estudo, que, após a identificação da metodologia de custeio por atividades $(A B C)$, se pôs à aplicação, por intermédio de um estudo de caso - realizado por observação in loco e pesquisa documental - em uma organização hoteleira em implantação, incrementando significativamente as contribuições do estudo e demonstrando sua real aplicabilidade prática.

\section{FORMAÇÃO DE PREÇOS}

O acirramento da competitividade tem levado os gestores a buscar alternativas de maximização dos lucros. Como o cenário não permite aumentos constantes de preços, a redução de custos e a manutenção da qualidade dos produtos e dos serviços compõem boa parte dos esforços gerenciais. Nessa perspectiva, um processo confiável de formação de preços, também denominado de precificação, é essencial para a viabilidade econômica do negócio (RAMOS; CRUZ, 2012).

Por se tratar de um processo, etapas são necessárias. Ching (2006, p. 123) apresenta um roteiro de seis etapas para uma precificação adequada. A 
primeira envolve a compreensão sobre quais objetivos a empresa pretende alcançar com o preço; dentre eles podem estar: o retorno sobre o investimento, a expectativa de market share, a competitividade frente à concorrência ou a própria sobrevivência no mercado. A segunda envolve a compreensão sobre os fatores determinantes da demanda por produtos ou serviços, utilizando-se de elementos como o valor percebido pelo cliente e a elasticidade da demanda.

Em seguida se devem conhecer os determinantes de custos, desde a concepção do produto até sua "morte", para passar então para análise da concorrência, a fim de constantemente perseguir novas formas de vantagem competitiva. A quinta etapa se refere à seleção de um método de precificação que envolva os 3C's: custos, concorrência e clientes, de modo a, respectivamente, dispor de recursos para os gastos; ser competitivo; e atender às expectativas das demandas.

A sexta e última etapa envolve a seleção do preço final, a qual deve ser dirigida pelas seguintes perguntas: Quanto vale o meu produto para o cliente? Como posso comunicar melhor o valor para justificar o preço?; e que preço o cliente está disposto a pagar? (CHING, 2006).

Além desses aspectos, a habitual necessidade de geração de lucros foi cercada de alterações de ordem estrutural nos processos de formação de preços, que evoluíram de acordo com o comportamento, inicialmente das variáveis de mercado e, posteriormente, das expectativas de rentabilidade.

Do ponto de vista cronológico, a formação de preços evoluiu claramente de uma prática baseada em custos para uma prática baseada na aceitação do mercado. Na primeira abordagem o acionista ainda poderia determinar o lucro desejado, já na segunda o lucro passou a ser consequência do custo incorrido e dos preços praticados. Assim, o preço, antes livremente estipulado, passou de elemento variável para predeterminado pelo mercado, assumindo características de valor fixo.

Na perspectiva atual, em que a margem de lucro é uma função entre o preço praticado pelo mercado e os custos incorridos, o custo alvo (target costing) se apresenta como uma necessidade gerencial para o alcance das expectativas de rentabilidade (KATO, 2012). 
O presente e o futuro reservam, portanto, a necessidade de controles aprimorados de custos e despesas, de modo que organizações possam sobreviver diante dos cenários expostos e melhorar suas estratégias e estruturas de precificação, potencializando resultados.

Nesse cenário, os custos revelam sua significância ao passo que estratégias de aumento de preços ou de volume nem sempre são possíveis pelas restrições de mercado, ao contrário das estratégias baseadas em custos que podem ser revistos e atenuados por uma gestão eficiente (ZORNIG, 2007).

Padoveze (2003) sustenta que, se o preço é dado pelo mercado, não haveria justificativa em considerar os custos na formação de preços, sendo elemento imprescindível e direcionador de decisões de fabricar ou não o produto e de viabilidade de ofertá-lo.

Denota-se que a formação de preços consiste em três vertentes: dos custos, da concorrência (teoria econômica) e dos consumidores (mercado). Ainda que possíveis se empregadas separadamente, o ideal é uma prática sistêmica da precificação e não isolada a uma única área (RAMOS; CRUZ, 2012).

Bruni e Famá (2012) incluem a essa perspectiva holística a qualidade do produto em relação às necessidades do consumidor, o nível de produção e de vendas, os custos e as despesas de fabricar, administrar e comercializar o produto, complementando Ching (2006) quanto à concorrência em produtos, comportamentos da demanda e do mercado de atuação, além de ponderar sobre produtos substitutos, demanda, mercado de atuação e restrições.

A simples tarefa de fixar um preço equivale a apenas reagir ao mercado, enquanto precificar estrategicamente significa administrar suas condições (LORANDI; BORGES, 2011). Logo, precificar envolve entender os preços que podem ser cobrados e os custos incorridos, primando pelo equilíbrio entre os elementos que compõem o preço, recaindo sobre os custos uma atenção especial, haja vista sua importância para a competitividade e a rentabilidade. 


\section{FORMAÇÃO DE PREÇOS BASEADA NA CONCORRÊNCIA}

Em teoria econômica os preços são formados em decorrência da oferta e da procura (ROCHA JÚNIOR, 2012). Diante disso, os preços são balizados conforme a concorrência, e a partir dos preços identificados avaliam-se pontos fortes e fracos, a fim de explorá-los e contrabalançá-los, mas sem praticar os mesmos preços da concorrência indiscriminadamente (BRUNI; FAMÁ, 2012).

Quando há a comparação com a concorrência, a fim de ampliar o valor percebido pelo cliente, o preço pode ser firmado acima, abaixo ou no mesmo nível (PADOVEZE, 2003). Pesquisas informais de mercado; envio de clientes para a busca por informações da concorrência ou mesmo troca de informações entre as empresas são atitudes típicas (LORANDI; BORGES, 2011). Porém, de modo geral, as empresas de menor porte acabam seguindo o preço das empresas com melhores condições estruturais de fazê-lo (ZANELLA, 2001).

Analisar a concorrência para a precificação perpassa a compreensão da estrutura de mercado no qual a empresa opera, ao passo que influencia tanto o lado da oferta e da demanda, quanto os custos a serem incorridos na manutenção no mercado (HANSEN; MOWEN, 2010). Para Bruni e Famá (2012), existem quatro diferentes tipos de mercado que influenciam a definição de preços com base na concorrência: a) concorrência pura, com muitos compradores e vendedores, comercializando um produto uniforme de características iguais. Logo, nenhum comprador ou vendedor consegue isoladamente interferir nos preços de mercado; b) concorrência monopolista, com muitos compradores e vendedores, com possibilidade de trabalhar com diferentes preços em função da diferenciação dos produtos ou serviços; c) concorrência oligopolista, marcado pela existência de um pequeno número de vendedores, que acabam sendo muito sensíveis a preços e estratégias uns dos outros. O pequeno contingente de vendedores é decorrente das barreiras à entrada de novos vendedores; e d) monopólio puro, formado por um único vendedor, proveniente de um monopólio governamental ou privado regulado ou não regulado. Em razão disso, o produto é único e, como o preço é determinado pela empresa, ela pode cobrar um preço mais elevado (HANSEN; MOWEN, 2010). 
Lorandi e Borges (2011) alertam para a importância de conhecer, em especial e a fundo, os concorrentes com o mesmo cliente alvo, mas também ficar alerta para os demais concorrentes que incorporam o setor. Nessa estratégia cabe avaliar como o aumento e a diminuição do preço afetarão a participação de mercado e a lucratividade.

\section{FORMAÇÃO DE PREÇOS BASEADA NO CONSUMIDOR}

Quando se considera o valor percebido pelo consumidor, empregamse preços que o consumidor esteja disposto a pagar pelo produto; assim os preços acabam se ajustando ao valor percebido pelo cliente. Esse valor refere-se à relação entre os aspectos desejados pelo consumidor e aqueles que são atendidos pelo produto ou serviço (BRUNI; FAMÁ, 2012), sendo que "[...] os consumidores são mais sensíveis ao valor do que ao preço" (LORANDI; BORGES, 2011, p. 3).

Em consonância com Rocha Júnior (2012), fixar preços pelo valor percebido pelo cliente é uma metodologia orientada pelo mercado, em que antecipadamente se identifica o grau de utilidade ou o valor que um produto induz à mente do consumidor.

Canever et al. (2012) alertam para a imprescindibilidade de compreender os diferentes segmentos de clientes no mercado e assim praticar preços personalizados aos clientes-alvo. Tentar atender a todos os públicos indiscriminadamente dificilmente trará bons resultados. Isso decorre do fato de os consumidores possuírem diferentes perfis em relação a suas necessidades, preferências, desejos e poder aquisitivo, que por sua vez definem o quanto estarão dispostos a pagar por determinado produto. É por conta disso que diferentes clientes poderão perceber o valor de um produto de modos diferentes (LORANDI; BORGES, 2011).

Nesse sentido, a empresa precisa conhecer muito bem seu mercado e seu produto para avaliar se poderá vender a um preço mais alto, atraindo um público de renda mais elevada, ou se venderá a um preço popular, atraindo classes sociais mais baixas e ganhando em economias de escala (SANTOS, 2012). 
A importância dessa metodologia decorre do fato de o preço não ser o único elemento avaliado pelo consumidor, sendo apenas mais um dos vários atributos a ser percebido e avaliado pelo cliente, que fundamentam sua escolha por determinado produto ou serviço. É um processo bastante subjetivo, no qual dentro da estratégia escolhida pela empresa deve-se agregar valor aos produtos ou aos serviços ofertados (PINTO; MOURA, 2011).

São quatro os tipos de benefícios que se pode tentar ampliar para agregar valor ao produto: benefícios funcionais (funcionalidade, qualidade, embalagem), benefícios sociais (impressões pessoais de terceiros sobre a posse de um produto ou utilização de um serviço), benefícios pessoais (sentimentos experimentados pela compra), benefícios experimentais (prazer sensorial obtido com a compra) (LORANDI; BORGES, 2011).

Dentre as técnicas utilizadas para identificar quanto o consumidor está disposto a pagar, Pinto e Moura (2011) elencam: as técnicas de mensuração de valor do valor percebido de forma indireta ou direta, o price sensitive meter, a técnica de gabor-granger, o point-of sale e o brand-rice trade-off.

Conhecer como o consumidor se comporta em relação ao preço e ao valor percebido fornece balizas de como compor o preço, defendê-lo e torná-lo mais aceitável, bem como de possíveis adequações do próprio produto ou serviço em relação a seus custos e atributos.

O cerne da questão nesse método de formação de preços reside em saber o maior preço possível a ser praticado com base no que o consumidor está disposto a pagar dentro dos volumes de demanda. Adotam-se, assim, estratégias para criação de valor de mercado ao produto (ROCHA JÚNIOR, 2012).

\section{FORMAÇÃO DE PREÇO BASEADA EM CUSTOS}

O método baseado em custos também é chamado de precificação de dentro para fora, em função de ser o único método de formação de preços que considera informações internas (MARTINS, 2010). Formar preços baseados em custos parte do pressuposto que o mercado está disposto a absorver os preços propostos e calculados em cima dos custos e dos investimentos realizados (ROCHA JÚNIOR, 2012). 
No entanto, é importante considerar que, embora não se olhe inicialmente para o mercado, o que se pretende não é a desvinculação deste, mas assegurar, antes de qualquer coisa, que o preço praticado não incorra em prejuízos e inviabilize o empreendimento. Portanto os custos são a base para a determinação de limites de preços mínimos, sobrevindo a necessidade de sintonizá-los com o mercado ulteriormente, em que se poderá determinar se os preços podem ser maiores ou menores, dependendo dos elementos que permitam oferecer o mesmo produto e serviço que a concorrência (PADOVEZE, 2003).

Assim, de um modo ou de outro os custos precisam ser levados em consideração, uma vez que fornecem parâmetros para análises de estratégias de preços. A validade gerencial dessa metodologia de formação de preços reside na necessidade de avaliar a rentabilidade dos investimentos em relação aos custos e às despesas para fabricação e venda dos produtos (PADOVEZE, 2003).

Hansen e Mowen (2010) apontam que a precificação baseada em custos é usualmente utilizada em serviços e no comércio em razão da dificuldade e do tempo necessário para precificar de acordo com a oferta e a demanda, quando se tem uma gama de produtos muito extensa, sendo mais simples a precificação por custos para posterior adequação ao mercado.

São diversos os métodos de custeio existentes, e todos apresentam um único objetivo, o de determinar custos; no entanto cada um adota sistemáticas diferenciadas. No presente artigo serão utilizados o custeio por absorção e o custeio baseado em atividades (ABC).

Ressalta-se que os sistemas de custeio atuais precisam fornecer subsídios para a tomada de decisões que resultem na melhoria do desempenho empresarial, é nesse sentido que atua o método $A B C$. Nele a empresa é dividida em atividades, calculando-se os custos e as despesas de cada uma por meio da identificação dos recursos consumidos por elas e da compreensão do comportamento dessas atividades para, enfim, conforme a intensidade de uso das atividades, alocálas aos produtos. $O A B C$ "pressupõe que as atividades consomem recursos, gerando custos, e que os produtos usam tais atividades, absorvendo os custos" (BORNIA, 2010, p.112). É um sistema de custeio indicado, por fornecer uma estimativa mais realista dos custos, permitindo análises mais corretas e menos 
equivocadas sobre as estratégias de preços a serem adotadas e como estas impactarão no lucro (ZORNIG, 2007).

Já o método de custeio por absorção é o único sistema de custos que atende aos princípios contábeis e é aceito pela legislação fiscal para apuração dos custos dos produtos e, por consequência, do lucro tributável, uma vez que todos os gastos devem ser distribuídos em custos e despesas, atribuindo-se todos os custos aos produtos fabricados, enquanto as despesas são levadas diretamente para o resultado do período. Não obstante, acaba sendo o método mais utilizado pelas empresas (BORNIA, 2010).

No método baseado em custos, visa-se adicionar algum valor aos custos, usualmente por meio de uma margem padrão de lucro. Para tanto, alguns elementos são importantes para a definição do preço, dentre eles os impostos, os custos, as despesas e a margem de lucro. Inúmeros outros fatores podem afetar a margem de lucro, mas tendem a ser de cunho momentâneo, relativo ou subjetivo, tais como: o setor de atuação, o tipo de produto, a competitividade do setor, os cenários, etc. Assim, algumas metodologias para formação de preços podem ser adotadas, sendo elas: o mark-up, um fator multiplicador a ser aplicado sobre os custos e o retorno do investimento em um determinado prazo.

\section{PRESSUPOSTOS DA PRECIFICAÇÃO PARA HOTÉIS}

No comércio a formação de preços usualmente é simples, em especial, por envolver poucas variáveis e ser de fácil coleta de dados. Na indústria, os modelos de precificação tornam-se mais robustos em função da maior complexidade em definir o peso da matéria-prima no produto acabado, bem como o valor da mão de obra direta e dos custos indiretos envolvidos na produção. Contudo, nos serviços a atividade de formação de preços é de difícil execução, em virtude da diversidade e da variabilidade de fatores que podem ser computados na formação de preços, sobretudo, quando se refere à mão de obra, cujo tempo despendido a cada cliente poderá ser diferente, além de estar sujeito a maiores condições de ociosidade e oscilação (ASSEF, 2002). Acrescenta Zornig (2007) que, em decorrência da intangibilidade e da variabilidade dos serviços, bem como pela flexibilidade e customização que normalmente são exigidos, a 
definição do preço se torna muito mais complexa para um serviço do que para um produto, resultando em uma política de preços com muitas variáveis e nem sempre transparente.

Tal é a complexidade que Planagumà e Julve (2012) propõem um extenso conjunto de elementos a serem avaliados para um processo de formação de preços adequado em hotelaria, dentre eles: a análise do histórico de dados do hotel, de até dois anos, que sirvam para prognosticar o futuro; as características do hotel (se é novo, se possui acessibilidade a portadores de necessidades especiais, vista do hotel, imagem da marca); a classificação do hotel; a análise das alterações de reserva e como impactam no overbooking; a duração das estadias; a avaliação da demanda real e potencial; os indicadores de ocupação; o espaço temporal com que se realizam as reservas; a realização de eventos e a sua periodicidade (onde se localizam, quanto tempo duram); a segmentação de mercado e os diferenciais para cada grupo, conhecimento dos concorrentes, seus produtos e preços.

Todos esses indicadores são importantes para o estabelecimento de preços, especialmente para a criação de promoções de acordo com o tempo da estadia, antecedência da reserva, aproveitamento de dias ociosos e de como reverter reservas não concretizadas. No entanto, sua principal contribuição é a fixação de preços máximos e mínimos, e de como os preços das diárias oscilarão nesses patamares, conforme se alteram as condições do mercado e do consumidor. Assim é possível o estabelecimento de parâmetros para que em diferentes situações seja possível operar com diferentes preços (PLANAGUMÀ; JULVE, 2012).

Considerando a importância dos consumidores na determinação de preços, Schamel (2012) alerta para dois tipos de hóspedes, aqueles a negócios, que geralmente possuem estadias no decorrer da semana; e aqueles a lazer, que possuem estadias aos finais de semana. Em pesquisa realizada pelo autor se constatou que, enquanto o primeiro grupo é menos sensível ao preço, o segundo valoriza mais a localização, indicando, portanto, a análise de entrega de valor e de preço diferenciada para esses dois grupos de clientes.

Em contraponto, Lee (2015) adverte que, embora a localização seja o atributo mais valorizado pelo consumidor na hotelaria, não é determinante na 
substituição da preferência do consumidor, também sendo influenciado pela qualidade. Por conta disso, entende o autor que as estratégias de competição dos hotéis que usualmente são baseadas no preço, em função do aumento do nível de substituição na hotelaria, devem voltar-se mais para a competição por diferenciação por meio da qualidade, reafirmando, portanto, a necessidade de análise da concorrência a partir da similitude de características para a formação de estratégias de preços, e não simplesmente pela proximidade geográfica.

Em especial atenção aos custos, Lunkes (2009) observa que um hotel gera um grande montante de gastos pequenos com materiais, gastos elevados com mão de obra e custos fixos expressivos em razão da depreciação do imóvel e dos equipamentos. Ademais, face às necessidades de modernização, elevam-se ainda mais os gastos indiretos com o uso de máquinas e software. Assim, embora os custos diretos com mão de obra possam ter diminuído em decorrência dos avanços na automação, em contrapartida os custos indiretos se elevaram em $60 \%$. Nesse viés, Pereira (2009) explica que os principais custos de um hotel são os fixos, e que por não estarem diretamente relacionados aos produtos, acabam sendo de difícil alocação.

Diante dessas perspectivas, Zanella (2011) apresenta uma modelagem para a apuração de custos e preços na hospedagem. Segundo o autor, esses procedimentos compreendem os seguintes elementos: cálculo da taxa de ocupação, preço das diárias de hospedagem, apuração do custo de hospedagem, estabelecimento do ponto de equilíbrio de vendas e análise comparativa da evolução dos custos e dos preços. A taxa de ocupação revela-se como o principal item de controle de um hotel, a qual consiste na relação percentual entre o número de unidades habitacionais ocupadas e o número de unidade habitacionais existentes num dado período de tempo. Também podem ser considerados a diária média e o RevPAR (Revenue per Available Room), que é a receita por unidade habitacional disponível.

\section{PROCEDIMENTOS METODOLÓGICOS}

Cada pesquisa possui especificidades que determinam o alcance dos resultados desejados e a validade dos mesmos, de modo que diferentes necessidades e situações são preenchidas com diferentes métodos de 
pesquisa, que inclusive podem ser conjugados (YIN, 2010). Como não há uma classificação cogente da pesquisa, mas diferentes modos de classificação, no presente trabalho se optou por seguir Gil (2010), que propõe que as pesquisas sejam classificadas em relação à finalidade, aos objetivos e aos métodos empregados.

Quanto à finalidade, a presente pesquisa é classificada como aplicada, considerando que a busca de conhecimentos visa à aplicação em uma situação específica (GIL, 2010).

No que concerne aos objetivos é exploratória e descritiva. Esta, por descrever características da empresa para análise e construção de uma proposta de precificação, bem como os passos realizados para tanto; aquela em função de essas pesquisas permitirem maior familiaridade com o problema, tornando-o mais explícito, voltando-se para a análise dos mais variados aspectos sobre o fato ou o fenômeno estudado (GIL, 2010), permitindo ao pesquisador aumentar sua experiência em torno de determinado problema (TRIVIÑOS, 1987).

Como método, optou-se por desenvolver a pesquisa via estudo de caso, que, sinteticamente, possui como objetivo aprofundar os aspectos característicos de um objeto de pesquisa restrito, detalhando o fenômeno e indicando propostas de ação para este (GONSALVES, 2007). Destaca-se que o objeto foi escolhido em função de se tratar de um empreendimento em implantação, cujo acesso por parte dos autores se tornou facilitado, dada a proximidade familiar.

Quanto à abordagem da pesquisa, classifica-se como qualitativa, por se ater à compreensão e à interpretação do fenômeno, entendendo o contexto e a dinâmica da organização. Logo, a pesquisa está orientada qualitativamente pela estruturação do $A B C$ e a avaliação da concorrência para determinação de um preço adequado para o caso em tela.

Quanto aos procedimentos, foi bibliográfico, por desenvolver uma investigação de conhecimentos sistematizados em livros, artigos, dissertações e monografias, analisando a temática de acordo com as contribuições teóricas buscadas; foi documental por apoiar-se em documentos disponibilizados pela organização em estudo (GONSALVES, 2007), bem como por envolver 
informações disponíveis em sites de concorrentes e sites especializados em fornecimento de itens de uso e consumo para a organização em estudo; foi de campo, pelo fato de a pesquisa ter sido realizada na própria organização (BARROS; LEHFELD, 2012), no que se refere aos dados do objeto em estudo; e, em outras organizações, no que se refere aos dados necessários à composição dos custos utilizados no desenvolvimento do estudo (fornecedores), e na coleta de informações sobre a concorrência.

A pesquisa está fundamentada em duas dimensões: a de conhecer os custos por meio do orçamento por atividades e do custeio por absorção, e a de conhecer os preços de mercado, sendo estas as bases para uma precificação adequada interna e externamente ao empreendimento em evidência.

A dimensão de precificação baseada em custos teve como meta a identificação dos custos totais projetados pelo custeio por atividades e, posteriormente, pelo custeio por absorção, com vistas ao estabelecimento de preços, tomando por base também a rentabilidade esperada.

A dimensão de precificação competitiva envolveu um comparativo de preços do mercado no qual o empreendimento estará atuando, a fim de que o hotel em estudo seja comparado com seus pares. Os critérios para comparação foram estabelecidos a partir de uma adequação do modelo proposto por Freitas (2007), avaliando-se elementos de estrutura física (TV, frigobar, ar-condicionado, TV a cabo, elevadores ou até dois andares de escada, sala de jogos, piscina, sauna, cama box), serviços (arrumadeira, carregador de bagagem, serviço de refeição no quarto, serviço de internet, lavanderia para hóspedes, estacionamento incluso, cofre, café da manhã incluso) e preço. A partir da identificação do universo de concorrentes, estes foram classificados em função dos critérios, formando-se grupos estratégicos, os quais foram determinados conforme a similaridade de itens atendidos, e não pela similitude de preços, tendo em vista que preços iguais podem oferecer diferentes estruturas físicas e serviços. Isso significa que primeiro foram comparados em termos de recursos oferecidos e ulteriormente em termos de preços. 
O hotel em estudo caracteriza-se por ser de pequeno porte e familiar. Encontrase em fase de construção. O empreendimento terá foco econômico voltado para executivos em viagens de negócios, sugerindo alta taxa de ocupação de segunda à quinta-feira e baixa ocupação aos finais de semana. A perspectiva é que a taxa de ocupação chegue a $80 \%$ durante a semana, mas em função da baixa ocupação aos finais de semana, a taxa média de ocupação mensal deve cair para $60 \%$. Essa taxa de ocupação ainda sofre alterações em decorrência das fortes oscilações na procura decorrente de eventos de negócio na cidade.

Possuirá 68 apartamentos de mesmo padrão interno, diferenciando-se apenas por serem duplos e de casal. Os apartamentos possuirão $12 \mathrm{~m}^{2}$ e serão equipados com frigobar de 80 litros, climatizadores de 7.000 BTU's, cofres e televisores LED de 36 polegadas. Serão oferecidos os serviços de TV a cabo, internet wi-fi, telefone, estacionamento e café da manhã.

\section{PRIMEIRA DIMENSÃO: PRECIFICAÇÃO BASEADA EM CUSTOS}

Na equação do preço há de se considerar, além dos custos totais apurados, a margem de lucro almejada pelo investidor e os impostos incorridos na atividade.

O valor do investimento final a ser realizado no hotel chega à casa dos $\mathrm{R} \$ 2.300 .000,00$. O objetivo do proprietário é que o retorno do capital investido ocorra em até 4 anos. Isso significa que a cada ano o empreendimento deveria gerar um lucro líquido de ao menos $R \$ 575.000,00$ anuais, ou $R \$ 47.916,67$ mensais, o que representa $25 \%$ ao ano e $2,08 \%$ ao mês, se constituindo assim na base de valor para o cálculo da margem de lucro a ser incorporada ao preço.

No que concerne aos impostos, por se tratar de um pequeno empreendimento e se enquadrar no regime Simples Nacional, que abrange o IRPJ, a CSLL, o PIS/Pasep, a Cofins, o ICMS, o ISS e a Contribuição para a Seguridade Social 
destinada à Previdência Social a cargo da pessoa jurídica, estima-se uma alíquota de $12,2 \%$.

Considerando o cálculo do preço em função do capital investido, empregase a fórmula do Quadro 1 no presente estudo.

Quadro 1. Fórmula do preço pelo capital investido

\section{$1 P-0,122 P=\underline{\text { Custos totais }+ \text { Despesas totais }+ \text { (Capital investido } \times \text { taxa de retorno) }}$ Unidades vendidas}

Fonte: Elaborado com base em Dubois, Kulpa e Souza (2009) e Ching (2006).

\section{CUSTEIO BASEADO EM ATIVIDADES PARA FORMAÇÃO DO PREÇO}

A apuração dos custos por meio do $A B C$ envolve a identificação das principais atividades do hotel, para posteriormente apurar como essas atividades são consumidas pelos produtos/serviços (objetos de custos).

Durante o estudo se evidenciaram cinco principais atividades, quais sejam: apoio à estadia do hóspede, limpar e manter, alimentação, segurança e gerenciar. Dentre estas, a atividade de gerenciar e de segurança se caracteriza por ser de natureza secundária, ou também denominada de indireta, uma vez que oferece suporte para as demais atividades, sendo estas denominadas de primárias ou diretas.

Sobre os custos, cabe a ressalva sobre a mão de obra no que concerne à ociosidade. Em função na oscilação da demanda no mercado hoteleiro de Chapecó, que é especialmente movimentado por eventos de negócios e não de turismo, o que acarreta diferentes taxas de ocupação nos dias de semana e aos finais de semana, bem como em determinadas épocas do ano, implicando alterações com custos de mão de obra em função dessa sazonalidade, os custos podem reavaliados.

Conhecendo-se o gasto total com cada recurso, por meio dos direcionadores, foi possível a distribuição dos recursos a cada atividade com a qual mantinham relação, compondo o custo de cada atividade. Para o custo final das atividades 
resta a distribuição das atividades indiretas de gerenciar e de segurança. $\mathrm{O}$ custo final, das atividades, é apresentado na Tabela 1.

Tabela 1: Custo das atividades

\begin{tabular}{c|c|c|c|c}
\hline & Apoio à estadia & Limpar e Manter & Alimentação & TOTAL \\
\hline Recursos & $4.672,26$ & $2.671,83$ & $2.254,58$ & $9.598,66$ \\
Gerenciar & $2.653,73$ & 884,58 & 884,58 & $4.422,89$ \\
Segurança & $1.938,89$ & 0,00 & 0,00 & $1.938,89$ \\
\hline TOTAL & $9.264,88$ & $3.556,40$ & $3.139,16$ & $15.960,44$ \\
\hline
\end{tabular}

Fonte: Elaborado pelos autores.

O custo final dos objetos de custo, expresso na Tabela 2, é obtido pela proporção das atividades consumidas por eles e pelos recursos diretos.

Tabela 2: Custo final dos objetos de custo em R\$

\begin{tabular}{c|c|c|c}
\hline Custo & Ap. Duplo & Ap. Casal & TOTAL \\
\hline Recursos diretos & $29.255,70$ & $15.071,12$ & $44.326,82$ \\
Atividades primárias & $10.533,89$ & $5.426,55$ & $15.960,44$ \\
TOTAL & $39.789,59$ & $20.497,67$ & $60.287,26$ \\
\hline TOTAL UNIT. & 29,47 & 29,71 & \\
\hline
\end{tabular}

Fonte: Elaborado pelos autores.

Formado o custo e observando ainda a rentabilidade almejada, parte-se para a formação do preço, a qual considerou que todas as diárias mensais disponíveis sejam vendidas, as quais totalizam 1350 diárias dos apartamentos duplos, e 690 para os apartamentos de casal. Considerou, ainda, o lucro unitário, isto é, a margem de lucro de referência de $R \$ 47.916,67$ pela quantidade de diárias mensais disponíveis, de 2040 unidades, totalizando uma expectativa de $\mathrm{R} \$ 23,49$ de lucro por diária.

Tabela 3: Cálculo proporcional do preço das diárias

\begin{tabular}{|c|c|c|c|c|c|c|c|}
\hline \multirow{2}{*}{\multicolumn{2}{|c|}{ Item }} & \multicolumn{2}{|c|}{ AP. DUPLO } & \multicolumn{2}{|c|}{ AP. CASAL } & \multicolumn{2}{|c|}{ TOTAL } \\
\hline & & Total & Unit. & Total & Unit. & Total & Unit. \\
\hline Custos e Despesas & $A B C$ & $39.789,59$ & 29,47 & $20.497,67$ & 29,71 & $60.287,26$ & 29,55 \\
\hline Mensais & Impostos & $9.923,21$ & 7,35 & $5.111,96$ & 7,41 & $15.035,17$ & 7,37 \\
\hline \multicolumn{2}{|c|}{ Margem de lucro } & $31.709,56$ & 23,48 & $16.207,11$ & 23,49 & $47.916,67$ & 23,49 \\
\hline \multicolumn{2}{|l|}{ Preço } & & 60,32 & & 60,59 & & 60,45 \\
\hline
\end{tabular}

Fonte: Elaborado pelos autores. 
$O$ custo identificado pelo $A B C$, os impostos e a margem de lucro esperada estão representados na proporção de apartamentos existentes de cada tipo, assim o preço calculado remunera apenas o custo, os impostos e o capital investido respectivo àquele tipo de apartamento, considerando uma taxa de ocupação de $100 \%$. Os preços formados por meio do $A B C$ são próximos, especialmente em razão dos custos também apresentarem pouca variação por tipo de apartamento, considerando que se constitui em um dos elementos que melhor poderiam explicar as diferenças de preços. Outro elemento que poderia ser avaliado é a possibilidade de rentabilidades diferentes para cada tipo de apartamento, considerando o volume de vendas ou ainda elementos competitivos.

\section{CUSTEIO POR ABSORÇÃO PARA FORMAÇÃO DO PREÇO}

Embora os elementos até o momento apresentados já formem indicativos para a propositura de uma estrutura de diárias, alguns aspectos ainda merecem atenção. Em virtude de o preço formado com base no $A B C$ considerar que todas as diárias mensais sejam vendidas, quando na realidade há uma média no mercado de $60 \%$ de ocupação, a qual também é prevista para o empreendimento, ainda se estuda a adequação do preço em função dessa expectativa de vendas. Portanto essa precificação se traduz em um avanço a partir do $A B C$, de modo a aprimorar o cálculo do preço original ao ser incorporada a expectativa de venda, utilizando-se do método de custeio por absorção para identificação de custos fixos e variáveis, que possibilitam o cálculo desse preço.

Calcular o preço com base nessa taxa de ocupação implica garantir que, com essa quantidade, sejam cobertos os custos variáveis dessas unidades, além de todos os custos fixos do empreendimento, mantendo também a rentabilidade esperada. Nesse sentido, o preço formado acaba se traduzindo no ponto de equilíbrio econômico (PEE).

Para tanto, foram identificados os custos fixos que perfizeram o total de $R \$ 27.930,18$ e, unitariamente, $R \$ 13,69$; e os custos variáveis que variáveis totalizam mensalmente $R \$ 32.357,08$, representando unitariamente $R \$ 15,86$. Com base nisso foi possível se chegar a um novo preço com a mesma fórmula anteriormente aplicada (Quadro 1). 
Importante explicar, que no caso de ocupação parcial, em função dos custos variáveis, que representam o custo adicional para cada diária a mais vendida, o custo total se altera proporcionalmente às vendas. O lucro total esperado continua sendo $R \$ 47.916,67$, no entanto o valor por diária se eleva de $R \$ 23,49$ $(A B C)$ para $R \$ 39,15$, uma vez que os custos fixos e o lucro passam a ser diluídos pela proporção de vendas mensais.

Na Tabela 4 se pode verificar o cálculo do preço das diárias para ambos os tipos de apartamentos, considerando o custeio por absorção.

Tabela 4: Cálculo do preço das diárias pela taxa de ocupação

\begin{tabular}{l|c|c|c}
\hline \multirow{2}{*}{} & \multicolumn{2}{c}{ Diárias } \\
\cline { 3 - 4 } \multicolumn{2}{c|}{ Item } & TOTAL R $\$$ & UNIT. R\$ \\
\hline \multirow{2}{*}{$\begin{array}{c}\text { Custos e Despesas } \\
\text { Mensais }\end{array}$} & Fixos & $27.930,18$ & 22,82 \\
& Variáveis & $19.414,25$ & 15,86 \\
\multicolumn{2}{c|}{ Impostos } & $13.236,73$ & 10,81 \\
\multicolumn{2}{c|}{ Margem de lucro } & $47.916,67$ & 39,15 \\
\hline \multicolumn{2}{c|}{ Preço } & & 88,64 \\
\hline
\end{tabular}

Fonte: Elaborado pelos autores.

Destaca-se que a cada diária a mais vendida com esse preço, incorrer-seia em um lucro líquido adicional (já descontado o custo variável e impostos) por diária em torno de $\mathrm{R} \$ 61,96$, aumentando a margem de lucro conforme oscilarem as vendas acima da taxa de ocupação de $60 \%$.

Considerando esse preço formado pelo ponto de equilíbrio econômico, quando se lança um olhar sobre o ponto de equilíbrio contábil, considerando esse preço, teriam de ser vendidas 466 diárias, o que se traduz em uma ocupação mensal de $22 \%$, para que somente as despesas fixas e as variáveis sejam pagas, ou seja, para que a empresa adquira lucro igual a zero e não opere com prejuízos. Cenário que se constitui favorável à empresa, que pode operar muito abaixo da expectativa de venda, sem estar incorrendo em prejuízos. 


\section{SEGUNDA DIMENSÃO: PRECIFICAÇÃO COMPETITIVA}

Baseado nos dados da primeira dimensão de precificação baseada em custos, há fundamentos para se estabelecer a adequação do preço firmado a partir de um comparativo de mercado.

Em Chapecó/SC, cidade que serve de objeto a este estudo, existem 24 hotéis em funcionamento e que compõem o universo de concorrentes diretos. Não foram considerados os concorrentes indiretos, como os motéis, que também oferecem pernoite, e nem os hotéis que estão em construção, que seriam 11; contudo cabe apontar sobre estes últimos, que quando iniciarem suas atividades, a competição se tornará mais acirrada e poderá alterar os parâmetros de competitividade atuais e ora avaliados. A partir da análise dos elementos de estrutura-física, serviços ofertados e preços, foram identificados quatro grupos estratégicos, caracterizados no Quadro 2.

Quadro 2. Formação de Grupos Estratégicos

Grupo estratégico

Grupo 1

Padrão Alto

Grupo 2

Padrão Intermediário Alto

Grupo 3

Padrão Intermediário Baixo
Possuem estrutura física completa e ampla gama de serviços. Sugerem um alto valor agregado e maior custo benefício em relação aos demais grupos. Diárias acima de $R \$ 200,00$, com média de $R \$ 250,00$.

Embora ofereçam o essencial ao conforto nos apartamentos, não oferecem opções de lazer, como sauna, piscina, sala de jogos e sala de ginástica. Quanto aos serviços, apesar de não contemplarem todos, oferecem alguns diferenciais, como lavanderia para hóspedes e serviço de refeição no quarto.

Diária média de $R \$ 188,00$.
Igualmente ao padrão intermediário alto, oferecem estrutura física básica para o conforto do hóspede, mas o pacote de serviços ofertados é menor, isto é, a relação custo/benefício é mais baixa no padrão intermediário alto.

Diária média de $R \$ 165,50$.
Grupo 4

Padrão Baixo
Possuem estrutura física e serviços básicos, apresentam diárias mais baixas. Baixo valor agregado à prestação do serviço. Diárias, no geral, entre $\mathrm{R} \$ 110,00$.

Fonte: Elaborado pelos autores.

O grupo com o qual o objeto de estudo deve ser comparado, isto é, que mantém relação de maior proximidade, é o Grupo 3 (padrão intermediário 
baixo), havendo compatibilidades de infraestrutura oferecendo o mínimo de conforto e serviços básicos de suporte ao hóspede. As diárias nesse grupo variam de $R \$ 129,00$ a $R \$ 210,00$, sendo que dos sete hotéis que compõem este grupo, quatro deles têm seu preço entre $R \$ 170,00$ a $R \$ 180,00$, o que induz a preços mais elevados que a média. Os preços para apartamentos duplos e de casal na maioria dos hotéis são os mesmos.

Ainda há de se observar que, quando se formam grupos estratégicos, embora a concorrência seja mais acirrada entre os hotéis dentro de um grupo, não se pode esquecer que também se deve competir com os hotéis de outros grupos, neste caso especialmente com aqueles dos Grupos Estratégicos 2 e 4: os consumidores que preferem diárias de baixo custo podem preferir hotéis deste grupo, e aqueles que priorizam o custo/benefício a partir da entrega de valor dos serviços prestados podem optar por hotéis do Grupo 2.

\section{ESTRUTURA DE DIÁRIAS PARA O OBJETO DE ESTUDO}

Com os alicerces formados nas duas dimensões apresentadas, nota-se que os dados obtidos na segunda dimensão são essenciais para a formação final dos preços, elevando a expectativa de rentabilidade. Por outro lado, os custos identificados na primeira dimensão se revelaram importantes para que a empresa em estudo conheça a si mesma, suas limitações e como pode manobrar o preço para que atenda a estes, podem auferir maiores lucros.

Em face disso e da estruturação proposta, é evidente que a contribuição do estudo reside na convergência entre as duas dimensões, encontrando-se nessa conexão a resposta da problemática proposta, isto é, a de propor uma precificação adequada ao empreendimento hoteleiro em estudo, possibilitando a aproximação do empreendimento com as variáveis ambientais internas e externas que o afetam.

Constatam-se duas situações importantes decorrentes do estudo de caso apresentado. Primeira: o cálculo de custos pelo $A B C$ realizado no presente estudo considerou uma projeção para uma ocupação de 100\%, porém há indicativos de uma ocupação menor, a qual é incorporada para o aprimoramento do cálculo do preço por meio do custeio por absorção; segunda: 
a rentabilidade dos concorrentes pode ser maior do que a rentabilidade esperada no empreendimento em estudo, permitindo assim uma revisão das expectativas de modo a incorporar acréscimos na margem de lucro calculada e, consequentemente, uma aproximação dos preços praticados pelo grupo estratégico onde se situa o empreendimento estudado.

Analisando esses dados, os preços baseados em custos indicam que o hotel possui flexibilidade para operar no mercado e oferecer preços diferenciados de acordo com o tipo de cliente, ou então para realizar promoções ou vender pacotes; haja vista sua segurança financeira ser facilmente atingida. Esse aspecto é muito importante quando considerada a sazonalidade negativa (quando as vendas se apresentam abaixo do esperado), ou ainda considerando as baixas vendas aos finais de semana, possibilitando que o hotel saiba como manobrar essa situação, atraindo consumidores com estratégias de preços diferenciadas da concorrência, sem prejudicar-se.

Quanto ao preço formado pelo $A B C$, embora ele se apresente abaixo da média de mercado e com lucros menores do que o esperado por haver a lotação de apenas $60 \%$ do hotel, caso o cenário favorável do mercado hoteleiro na cidade se altere, o hotel teria como competir com preços menores e ainda garantir a lucratividade, embora menor do que a almejada. Igualmente ocorre com o preço calculado pelo custeio por absorção, no entanto, esse, além de não relegar os custos incorridos, também atende a rentabilidade almejada.

No que concerne ao preço médio da concorrência no grupo estratégico 3, embora apresente uma lucratividade muito maior do que a esperada, ponderase que, por se tratar de um hotel novo, sua infraestrutura em relação aos outros hotéis seria um atrativo maior ao consumidor, mas por outro lado, não justificaria um preço mais elevado em relação aos demais, em função de a empresa estar entrando no mercado e ainda ter de conquistar clientes e se tornar conhecida no meio, o que indica uma estratégia de preços para penetração no mercado. Se optar por essa estratégia, a empesa teria de atuar abaixo da média identificada, podendo inclusive avaliar a possibilidade de adotar preços abaixo do mínimo encontrado nesse grupo, que é de $\mathrm{R} \$ 129,00$. Todavia essa estratégia deve ser muito bem ponderada por implicar a alteração da dinâmica concorrencial, que 
poderá passar a ser baseada unicamente na competição por preço. O importante é que, a partir desse comparativo de mercado, a empresa pode estabelecer suas próprias estratégias de atuação no mercado, não seguindo indiscriminadamente os preços praticados pelos concorrentes nem negligenciando seus custos.

Como a estratégia do proprietário do hotel é a de ser um provedor de baixo custo, os cenários tanto baseados em custos como baseados na concorrência acabam se coadunando para essa mesma perspectiva.

Nessa perspectiva o que se propõe é uma faixa de preços, apresentada no Quadro 3, que pode ser considerada para a definição do preço final pelo empreendedor, e que poderá variar de acordo a posição e a evolução da empresa no mercado, bem como do aprimoramento de sua gestão na área de custos.

Quadro 3. Faixa de preços

\begin{tabular}{|c|c|}
\hline Método de cálculo para precificação & Diárias R\$ \\
\hline Custeio baseado em atividades (ABC) & 60,45 \\
\hline Custeio por Absorção & 88,64 \\
\hline Grupo estratégico (GE) & 165,50 \\
\hline Média entre GE e ABC & 112,98 \\
\hline Média entre GE e Absorção & 127,07 \\
\hline Média entre GE, ABC e Absorção & 104,86 \\
\hline
\end{tabular}

Fonte: Elaborado pelos autores.

Considerando essa faixa de preços, o estudo sobre precificação realizado apontou os limites com base no custo e na rentabilidade, evidenciando ainda que o mercado pratica limites de preços diferentes, que indicam que a rentabilidade do negócio poderá se elevar, ou ainda possibilitar que o hotel se torne mais competitivo que os concorrentes, em termos de preços, podendo nessa perspectiva vender acima da expectativa, o que também implica maior rentabilidade.

CONCLUSÕES

Ao desenvolver o processo de formação de preços para a empresa objeto de estudo, viabilizou-se a construção de uma ferramenta que aprimore sua 
gerência e seus resultados, conferindo parâmetros internos relativos aos custos, e externos relacionados à concorrência, para o balizamento da competitividade.

Por meio da estruturação metodológica em duas dimensões, evidenciouse que a empresa em estudo encontra-se em uma posição favorável, considerando que há a possibilidade de, além de cobrir os custos, auferir uma rentabilidade acima da esperada pelo investidor. A partir desses elementos, estabeleceu-se uma sequência adequada de procedimentos para formação de preços na hotelaria.

Estabelecidas essas bases, o que se propôs não foi um preço, mas uma faixa de preços aceitável a ser praticada, entre um limite mínimo estabelecido pelos custos e pela perspectiva de rentabilidade, e um teto máximo indicado pela concorrência, cabendo ao gestor a determinação do preço final. Cabe salientar que, para o empreendimento ser viável do ponto de vista da rentabilidade almejada, o preço mínimo a ser praticado é o de $\mathrm{R} \$ 88,64$ (absorção), e não o de $R \$ 60,45(A B C)$, haja vista que o capital não seria remunerado na expectativa projetada. Ainda se identificou que a tomada de decisão desse preço converge para dois cenários: a adoção de um preço similar ao da concorrência para aumentar a rentabilidade do negócio ou aumentar a atratividade do hotel por meio de preços mais baixos, que implicaria um aumento de vendas e a superação do percentual médio de ocupação, também impactando em maior rentabilidade.

No tocante a tais observações, a proposta apresentada para a empresa cumpre efetivamente o papel ao qual se propôs em seus objetivos geral e específicos, sugerindo, com base no orçamento por atividades e de um comparativo de mercado, uma estrutura de preços de diárias.

Essa ferramenta ainda pode incorporar outros elementos não considerados. Para estudos futuros sugere-se a realização de análises CVL (custo-volumelucro) e a incorporação da ociosidade tanto do hotel quanto da mão de obra na composição de seus custos, possibilitando novas análises sobre os custos e para a formação de preços. Sugere-se ainda que o comparativo de mercado incorpore outros fatores, além da estrutura física e dos serviços ofertados, podendo ser atrelados pesos às variáveis. Ademais, a partir dos elementos 
abordados, podem ser criadas estratégias de marketing em termos de preços promocionais, por tipo de hóspede ou de acordo com a sazonalidade.

Cabe observar que o estudo encontra-se limitado pela falta de análise do valor percebido pelo cliente, que devido à sua importância deve ser incorporado em estudos futuros. Outras limitações estão relacionadas ao fato dos custos terem sido orçados e por não ter considerado no orçamento um benchmark dos custos dos concorrentes, que podem futuramente serem analisados.

Finalmente, destaca-se que a revisão dessa precificação deve ocorrer com a frequência em que se identificam mudanças conjunturais que justifiquem que os preços sejam alterados.

\section{REFERÊNCIAS}

ASSEF, Roberto. Manual de gerência de preços: do valor percebido pelo consumidor aos lucros da empresa. Rio de Janeiro: Campus, 2002.

BARROS, Adil de Jesus Paes de; LEHFELD, Neide Aparecida de Souza. Projeto de pesquisa: propostas metodológicas. 21. ed. Petrópolis: Vozes, 2012.

BORNIA, Antonio Cezar. Análise gerencial de custos: aplicação em empresas modernas. 3. ed. São Paulo: Atlas, 2010.

BRUNI, Adriano Leal; FAMÁ, Rubens. Gestão de custos e formação de preços: com aplicações na calculadora HP 12C e Excel. 6. ed. São Paulo: Atlas, 2012.

CANEVER, Felipe Pereira et al. Formação de preços: um estudo em empresas industriais de Santa Catarina. Revista de Contabilidade do Mestrado em Ciências Contábeis da UERJ, Rio de Janeiro, v. 17, n. 2, p.14-27, maio/ago. 2012.Disponível em: <http://www.e-publicacoes. uerj.br/index.php/rcmccuerj/article/view/5390/4096> . Acesso em: 18 out. 2013.

CHING, Hong Yuh, Contabilidade gerencial: novas práticas contábeis para a gestão de negócios. São Paulo: Pearson Prentice Hall, 2006.

DUBOIS, Alexy; KULPA, Luciana; SOUZA, Luiz Eurico de. Gestão de custos e formação de preços: conceitos, modelos e instrumentos, abordagem do capital de giro e da margem de competitividade. 3. ed.São Paulo: Atlas, 2009.

FREITAS, André Luís Policani. Uma abordagem multicritério para a classificação de hotéis. Revista de Administração - RAUSP, Universidade de São Paulo, v. 42, n. 3, p.338- 
DoI: 10.14210/rtva.v18n1.p106-133 348, jul. set. 2007. Disponível em: <http://www.redalyc.org/articulo.oa?id=22341743800>. Acesso em: 23 out. 2013.

GIL, Antonio Carlos. Como elaborar projetos de pesquisa. 5. ed. São Paulo: Atlas, 2010.

GONSALVES, Elisa Pereira. Iniciação à pesquisa cientifica. 4. ed. Campinas: Editora Alínea, 2007.

HANSEN, Don R, MOWEN, Maryanne M. Gestão de custos: contabilidade e controle. São Paulo: Cengage Learning, 2010.

KATO, Jerry. Curso de finanças empresariais: fundamentos de gestão financeira em empresas. São Paulo: M.Books do Brasil, 2012.

LEE, Seul Ki Lee. Quality differentiation and conditional spatial price competition among hotel. In: Tourism Management. n. 46, p.114-122. 2015. Disponível em: <http://link. periodicos.capes.gov.br/ >. Acesso em 28 out. 2015.

LORANDI, Joisse Antonio; BORGES, Thaiane Flor. Processo de precificação estratégica em indústria de roupas de acessórios de neoprene. In: Congresso UFSC de Iniciação Científica em Contabilidade, 4 , 2011, Florianópolis. Disponível em: <http://dvl.ccn.ufsc. br/congresso/anais/4CCF/20101109072645.pdf>. Acesso em 17 out. 2015.

LUNKES, Rogério João. Manual de contabilidade hoteleira: aspectos normativos, contabilidade, custos, análise das demonstrações contábeis, legislação fiscal e tributária, orçamento, gestão. São Paulo: Atlas, 2004.

MARTINS, Eliseu. Contabilidade de Custos. 10. ed. São Paulo: Atlas, 2010.

MORANTE, Antonio Salvador; JORGE, Fauzi Timaco. Formação de preços de venda: preços e custos, preços e composto de marketing, preços e concorrência, preços e clientes. São Paulo: Atlas, 2009.

PADOVEZE. Curso básico gerencial de custos: para cursos de administração de empresas, economia e engenharia. São Paulo: Pioneira Thomson e Learning, 2003.

PEREIRA, Mariana de Jesus. Prioridades estratégicas e gestão de custos: a relação conforme a percepção dos gestores nos hotéis de médio e grande porte da Cidade do Salvador - Ba. 2009. 126 f. Dissertação (Mestrado) - Curso de Ciências Contábeis, Setor de Ciências Sociais Aplicadas, Universidade Federal do Paraná, Curitiba, 2009. Disponível em: <http://www.ppgcontabilidade.ufpr.br/system/files/ documentos/Dissertacoes/D028. pdf>.>. Acesso em: 30 set. 2013. 
PINTO, Leonardo José Seixas; MOURA, Paola Cristina Cardoso. Formação do Preço de Venda e Estratégias de Precificação: o Caso da Leader Magazine. In SEGeT - Simpósio de Excelência em Gestão e Tecnologia, VIII, 2011. Disponível em: < http://www.aedb.br/ seget/arquivos/artigos11/25414331.pdf>. Acesso em: 08 out. 2013.

PLANAGUMÀ, Lluís Pratts. JULVE, Jaume Guia. Gestión de precios en un sistema de Revenue Management hoteleiro en línea. In: Pasos: Revista de Turismo y Patrimonio Cultural. v.10, n.5, p.511-520. 2012. Disponível em: < http://www.pasos online.org/Publicados/10512/ PS0512_06.pdf>. Acesso em 26 out. 2015.

RAMOS, Marco Aurélio; CRUZ, Nilza Rodrigues da. Anais. In: III CONGRESSO NACIONAL DE ADMINISTRAÇÃO E CIÊNCIAS CONTÁBEIS, 3., 2012, Rio de Janeiro. A formação de preços em uma empresa do setor hoteleiro do município de Uberlândia. Rio de Janeiro: Congresso Nacional de Administração e Ciências Contábeis, 2012. p. 1 - 14. Disponível em: <http:// www.facc.ufrj.br/ocs /index .php/adcont/adcont2012/paper/view/569>. Acesso em: 08 out. 2013.

ROCHA JÚNIOR, Cristiano Batista. Precificação estratégica: um estudo de caso em prestadoras de serviços automotivos. 2012. 65 f. Monografia - Curso de Ciências Contábeis, Departamento de Centro Sócio Econômico, Universidade Federal de Santa Catarina, Florianópolis, 2012. Disponível em: <https://repositorio. ufsc.br/bitstream/handle/ 123456789/103707/Cristiano Batista da Rocha Junior.pdf ?sequence=1>. Acesso em: 30 set. 2013.

SANTOS, Joel J. Fundamentos de custos para a formação do preço e do lucro. 5. ed. São Paulo: Atlas, 2012.

SCHAMEL, Guenter. Weekend vs. midweek stays: Modelling hotel room rates in a small Market. In: International Journal of Hospitality Management. n. 31. p.1113- 1118. 2012. Disponível em: < http://link.periodicos.capes.gov.br/>. Acesso em: 28 out. 2015.

TRIVIÑOS, Augusto Nibaldo Silva. Introdução à pesquisa em Ciências Sociais: a pesquisa qualitativa na educação. São Paulo: Atlas, 1987. Disponível em: <http://pt.scribd.com/doc/84 708933/Livro-Introducao-a-pesquisa-em-Ciencias-Sociais-Trivinos>. Acesso em: 27 abr. 2014.

ZANELLA, Luiz Carlos. Administração de custos em hotelaria. 2. ed. Caxias do Sul: EDUCS, 2001.

ZORNIG, Frederico. Acerte o preço: e aumente seus lucros. São Paulo: Nobel, 2007.

YIN, Robert K. Estudo de caso: planejamento e métodos. 4. ed. Porto Alegre: Bookman, 2010. 